\title{
Married women's decision making power on family planning use and associated factors in Mizan-Aman, South Ethiopia: a cross sectional study
}

Abeba Daniel Belay ${ }^{1}$, Zelalem Birhanu Mengesha², Manay Kifle Woldegebriel ${ }^{2}$ and Yalemzewod Assefa Gelaw ${ }^{2 *}$

\begin{abstract}
Background: Women's use of family planning service is influenced by many factors, especially by their decision making power. A woman's decision-making power, be it individual or decision made in collaboration with a partner, is the most important factor in the use of family planning in a household. The purpose of this study was to assess the impact of women's decision making power on family planning use and its associated factors.

Methods: A community-based cross-sectional study was conducted on married women in the child bearing age. The women who were living in Mizan city were selected using the simple random sampling method. Trained nurses collected the data by interview, using a structured and pre-tested questioner. Bivariable and multivariable binary logistic regression analysis was used to identify the associated factors, and the odds ratio with a $95 \% \mathrm{Cl}$ was computed to assess the strength of the association. Collinearity was also assessed by looking at standard errors in the final fitted model.

Result: Overall, more than two-thirds [67.2\%: $95 \% \mathrm{Cl}(63-71 \%)]$ of the married women were found to be more autonomous to decide family planning use. Secondary education [AOR: $9.04,95 \% \mathrm{Cl}$ : $(4.50,18.16)]$, government employment [AOR: 4.84, 95 \% Cl: $(2.03,11.52)$ ], being wives of government employed spouses [AOR 2.71, $95 \% \mathrm{Cl}$ : $(1.24,7.97)]$, having husbands with college or university education [AOR: 11.29, $95 \% \mathrm{Cl}$ : $4.66,27.35)$ ], and being in the younger age [AOR: $0.27,95 \% \mathrm{Cl}:(0.09,0.75)]$ were significantly associated with women's decision-making power on family planning.
\end{abstract}

Conclusions: In this study, women had a high decision making power in family planning use. Age category (34-44-years), formal education, and occupational status had effects on women's decision making power. Promoting parental adult education and engaging women in out of house employment is essential to improve their decision making power in using family planning.

Keywords: Married women, Decision-making power, Family planning, Mizan-Aman City

\footnotetext{
* Correspondence: yalassefa@gmail.com

${ }^{2}$ Institute of Public Health, College of Medicine and Health Sciences

University of Gondar, Gondar, Ethiopia

Full list of author information is available at the end of the article
} 


\section{Background}

Family planning is a major issue for many developing countries where poor maternal and child health care services are practiced [1-4]. Even though the Ethiopian Government supports maternal health services and has gained some improvements in contraceptive use in the last few years, the total fertility rate per woman (4.1) and maternal mortality remain high (676 deaths per 100,000) [5], while family planning use remains low, especially in the rural settings (38.1\%) [6]. Previous isolated studies indicated the relationship between women's decision making power and family planning use [7, 8]. The 2011 report of Ethiopian Demographic and Health Survey also confirmed that the proportion of family planning use was higher among women who decided individually without the collective involvement of their partners.

Independent decision making or decision making with communications with partners on family planning use has a substantial contribution to the improvement of maternal health [9]. Similarly, ensuring family planning access and allowing women to decide independently on the use of family planning is important in preventing unintended pregnancy [10].

Although women will be more benefited from their family planning use by achieving their human rights to health autonomy and decision making on family size [11], only less than one fourths of the women in Ethiopia are able to decide on family planning use by themselves [12].

Producing information on women's decision making power in family planning use at the household level and identifying associated factors has a paramount importance. However, the existing information in Ethiopia on this issue is often very limited, making the planning, implementation, and evaluation of family planning activities difficult for program planners. Therefore, this study highlighted the relationship between women's decision-making power, family planning use, and associated factors.

\section{Methods}

\section{Study design, period, and setting}

A community-based cross-sectional study design was applied from August 15 to 30/2013 in Mizan-Aman city administration which is located in Bench-Maji Zone, $227 \mathrm{Km}$ south of Addis Ababa, the capital city of Ethiopia. The total population of the city administration in 2013 was 34,080 of whom 15,942 were women [13]. One general hospital, a health center, and about 30 private clinics provided family planning services in the city administration.

\section{Sample size determination and sampling techniques} The sample size of the study was computed by the single population proportion formula using the Epi Info ${ }^{\text {mx }}$ version 3.5.3 Statcalc program considering: proportion(p) of independent decision-making on family planning use by urban married women (64\%) [7], level of significance $(\alpha=0.05)$, worst acceptable values (60 or $68 \%$ ), and $10 \%$ non-response rate. Finally, 608 was the final sample size of the study.

Married women in the age range of 15-49 years and lived at least for 6 months in the study area were selected using the simple random sampling techniques via a table of random generation. The list of the study population was obtained from health extension workers' (the lowest health professionals working at health posts). Before data collection, a sampling frame was designed by numbering the list of house owners using the registration book.

\section{Data collection procedures and instruments}

The primary data was collected by trained nures. A stractured and pretested questionarrie was used to collect the data. A half day training was given to the data collectors and supervisors on the objective, confidentiality of information, respondent rights, and the techniques of interview. Following the training, a pretest was administered ( $5 \%$ of the sample size:30 married women) out of the study area before the actual data collection.

Information on socio-demographic characteristics, reproductive related history, knowledge about family planning, and women's decision-making power were collected from married women. The collected data was checked for completeness and accuracy by the supervisors and the principal investigators on daily basis during the data collection process.

\section{Data management and analysis}

The decision making power of women in family planning use was measured in relation to their ability to freely decide individually, discuss with their partners about family planning needs and choices using eight questions. A score of 1 was given if women decided independently or together by discussing the use of family planning, number of children, choice of family planning methods, when to give birth, where to get family planning service, how to seek reproductive health services with no oppositions about using/intending to use family planning. Zero (0) was scored by partners who decided independently. Then woman who scored below the mean were considered as having no decision making power, and those who scored greater or equal to the mean were considered as having good decision making power [7].

Data were entered using the Epi Info ${ }^{\mathrm{mm}} 3.5 .3$ and exported to the Statistical Package for Social Sciences (SPSS) version 20 for analysis and further cleaning purposes. Since the outcome variable was dichotomous, 
binary logistic regression models (both bivariable and multivariable) were used to identify associated factors. The Hosmer-Lemeshow goodness-of-fit statistic (0.67) was used to assess the fitness of the model. Odds ratios (Crude: COR and Adjusted: AOR) with $95 \%$ confidence intervals $(\mathrm{CI})$ were calculated to measure the strength of the association. In the multivariable analysis variables with a p-value of $<0.05$ were considered as significant.

\section{Ethical consideration}

This study was carried out after getting ethical approval from the Institutional Review Committee of the Institute of Public Health, the University of Gondar. Before the approval, the proposal was sent to reviewers to assure ethical issues. Finally, the Ethical Review Committee approved the oral consent on the ground that the research had no serious harm on the study participants. Before the interview, the interviewer fully explained the purpose of the study to each participant and obtained full verbal informed consent. To ensure confidentiality, no names were used in the questionnaire and in reporting the results of the study.

\section{Result}

\section{Socio demographic characteristics of the respondents}

A total of 567 married women within the reproductive age (with a response rate of $93.26 \%$ ) participated in the study. The mean age $(\mathrm{SD})$ of the respondents was $29.53( \pm 6.79)$ years. The majority of the respondents were in the age group of 25-34 years. Three-fourths (79.4\%) of the women had attended primary school and above. Around $31 \%$ were housewives (Table 1 ).

\section{Reproductive history and knowledge of respondents}

The mean age at first marriage was 19.56 years with 2.72 SD. About $85 \%$ of the women had given birth to one or more children and the majority $(80.42 \%)$ had desire for more children.

Around $98.8 \%$ of the participants had heard about contraceptive and knew at least one method of family planning. The majority (95.2 \%) desired to know more about family planning methods. Injectables $(95.1 \%)$ were the most used family planning methods. Fifty-eight percent of mothers had discussed family planning methods with their partners, and $36.2 \%$ consulted health providers about the type of family planning and side effects (Table 2).

Women's decision making power on family planning use The overall proportion of women with a decisionmaking power was $67.2 \%$ [95 \% CI: (63-71\%).
Table 1 Socio-demographic characteristics of married women's decision making power in family planning use and associated factors in Mizan-Aman, South Ethiopia, 2013

\begin{tabular}{|c|c|}
\hline Variables & Frequency (\%) \\
\hline \multicolumn{2}{|c|}{ Age category of women } \\
\hline $15-24$ & $126(22.2 \%)$ \\
\hline $25-34$ & $278(49.0 \%)$ \\
\hline $35-44$ & $132(23.3 \%)$ \\
\hline $45-49$ & $31(5.5 \%)$ \\
\hline \multicolumn{2}{|l|}{ Ethnicity of women } \\
\hline Bench & $176(31.0 \%)$ \\
\hline Amhara & $120(21.2 \%)$ \\
\hline Kefficho & $110(19.4 \%)$ \\
\hline Tigre & $40(7.1 \%)$ \\
\hline Oromo & $48(8.5 \%)$ \\
\hline Gurage & $50(8.8 \%)$ \\
\hline Others $^{a}$ & $23(4.1 \%)$ \\
\hline \multicolumn{2}{|l|}{ Religion of women } \\
\hline Orthodox & $197(34.7 \%)$ \\
\hline Muslim & $88(15.5 \%)$ \\
\hline protestant & $255(45.0 \%)$ \\
\hline Others $^{\mathrm{b}}$ & $27(4.8 \%)$ \\
\hline \multicolumn{2}{|l|}{ Occupation of women } \\
\hline House wife & $176(31.0 \%$ \\
\hline Self employed & $219(38.6 \%)$ \\
\hline Governmental & $172(30.3 \%)$ \\
\hline \multicolumn{2}{|l|}{ Husbands occupation } \\
\hline Not employed & $81(14.3 \%)$ \\
\hline Self employed & $270(47.6 \%)$ \\
\hline Governmental & $216(38.1 \%)$ \\
\hline \multicolumn{2}{|c|}{ Women educational status } \\
\hline Can't read and write & $117(20.6 \%)$ \\
\hline Primary education & $207(36.5 \%)$ \\
\hline Secondary education & $162(28.6 \%)$ \\
\hline College/university & $81(14.3 \%)$ \\
\hline \multicolumn{2}{|c|}{ Husbands educational status } \\
\hline Can't read and write & $81(14.3 \%)$ \\
\hline Primary education & $161(28.4 \%)$ \\
\hline Secondary education & $170(30.0 \%)$ \\
\hline College/university & $155(27.3 \%)$ \\
\hline \multicolumn{2}{|l|}{ Exposure to media } \\
\hline Yes & $490(86.4 \%)$ \\
\hline No & 77 (13.6 \%) \\
\hline
\end{tabular}


Table 2 Knowledge of married women's decision making power in family planning use and associated factors in Mizan-Aman, South Ethiopia, 2013

\begin{tabular}{ll}
\hline Variables & Frequency (\%) \\
\hline Source of information & $247(43.6)$ \\
HEWs & $214(37.7)$ \\
Radio & $377(66.7)$ \\
Television & $277(48.9)$ \\
Health centers & $68(12.0)$ \\
Formal Education & \\
Places where to get FP services & $404(71.3)$ \\
Hospital & $432(76.2)$ \\
Health center & $141(24.9)$ \\
Health post & $227(40.0)$ \\
Pharmacy & $239(42.2)$ \\
Clinics & \\
Types of family planning methods & $425(75.0)$ \\
Pills & $344(60.7)$ \\
IUCD & $539(95.1)$ \\
Inject able & $361(63.7)$ \\
Implant/Norplant & $93(16.4)$ \\
Female condom & $136(24.0)$ \\
Tuba ligation & $68(12.0)$ \\
Vasectomy & $294(51.9)$ \\
Male condom & $169(29.8)$ \\
Emergency contraceptive & $181(31.9)$ \\
\hline
\end{tabular}

Factors associated with Women's decision making power in family planning use

Women's age, religion, educational status, occupation, exposure to media, partner's educational status and occupation, number of living children, discussion with partner about family planning, and attitude towards family planning methods had $p<0.2$ in the bivariate analysis and entered into multivariate analysis. Finally, in the multivariate analysis women's age, educational status, occupation and partner's educational status remained significantly associated with women's decision making power in family planning use (Table 3 ).

Young women in the age range of 34-44 years [AOR: 0.26, 95 \% CI: $0.09,0.47)$ ] were 3.8 times more likely to have a decision-making power on family planning use as compared to older women. Women who had attended primary school [AOR: 4.59, $95 \%$ CI: $(2.49,4.82)$ ], secondary school [AOR: 9.04, $95 \% \mathrm{CI}:(4.50,18.16)]$, and college/university [AOR: 4.84, $95 \%$ CI $(2.03,11.52)$ ] were more likely to have a decision-making power as compared to women unable to read and write. Similarly, women whose husbands had attended secondary school
[AOR: 6.28, 95 \% CI: $(3.01,13.07)]$ and college/university [AOR: 11.28, 95 \% CI: (4.65-27.34)] were more likely to have a decision-making power as compared to their counter parts.

Self-employed [AOR: 1.88, 95 \% CI: $(1.09,3.24)$ ] and government employed women [AOR: 4.10, 95 \% CI: $(2.11,7.96)]$ were more likely to have decision making power when compared to housewives. Similarly, women whose husbands were government employees were [AOR: 2.71, 95 \% CI: (1.23-5.94)] 2.71 times more likely to have a decision making power than women who had unemployed husbands.

\section{Discussion}

The empowerment of women has been reported to be a key to using family planning [14]. In developing countries most partners give inferior positions to women in all aspects of decision-making [7, 8, 14]. Consequently, women are either under collective decision-making with their partners and/or entirely rely on the male partner's decision on issues that affect their contraception usage and reproductive life. In addition to family planning use, empowering women has an important role in the reduction of maternal and new born mortality by preventing unintended pregnancy and unsafe abortion $[5,15,16]$. In this study, the magnitude of women's decision making power on family planning was $67.2 \%$ (95 \% CI: 63-71\%) which is consistent with a study done in Dawro Zone $64 \%[7]$, but higher than the national report of Ethiopia (25\%) [5, 17]. This discrepancy might be due to the fact that this study considered only urban women in one district, whereas the national survey considered both urban and rural dwellers of at least more than one district, and it might also be due to the difference in educational status, and cultural norms of the women in the study settings. This study also confirms that women's decision making power is consistent with studies done in India (68 \%) [18], Malawi (28.75 \%) [19] and Pakistan (28 \%) [20].

This study found out that women's employment status contributed to their decision making power in family planning use. Employed women are more likely to decide individually on family planning use which is in line with previous studies $[17,19,21,22]$ done in Ethiopia and other developing countries but negatively associated with studies done in southern Ethiopia [7]. This difference might be explained by the difference in job opportunities for urban and rural women.

Likewise, other previous studies [17, 19, 21-26] showed that the more educated the women and their partners, the more likely they were to decide on family planning use.

If a woman gets older and approaches menopause age, she may feel more confident to decide on family planning use individually and by discussing with her partner 
Table 3 Factors associated with married women's decision making power in family planning use and associated factors in Mizan-Aman, South Ethiopia, 2013

\begin{tabular}{|c|c|c|c|c|}
\hline \multirow[t]{2}{*}{ Explanatory variable } & \multicolumn{2}{|c|}{ Decision making power } & \multirow[t]{2}{*}{ COR $(95 \% \mathrm{Cl})$} & \multirow[t]{2}{*}{ AOR $(95 \% \mathrm{Cl})$} \\
\hline & $\overline{Y e s}$ & No & & \\
\hline \multicolumn{5}{|l|}{ Age } \\
\hline $15-24$ & 95 & 31 & 1 & 1 \\
\hline $25-34$ & 192 & 86 & $2.38(1.12-5.03)$ & $0.41(0.15,1.11)$ \\
\hline $35-44$ & 79 & 53 & $1.72(0.72-3.48)$ & $0.26(0.09,0.74)^{*}$ \\
\hline $45-49$ & 15 & 16 & $3.26(1.45-7.36)$ & $0.57(0.20,1.63)$ \\
\hline \multicolumn{5}{|l|}{ Women educational status } \\
\hline Can't read and write & 29 & 88 & 1 & 1 \\
\hline Primary school & 151 & 56 & $8.18(4.86-13.76)$ & $4.59(2.49,4.82)^{*}$ \\
\hline Secondary school & 139 & 28 & $14.52(8.09-26.06)$ & $9.04(4.50,18.16)^{* *}$ \\
\hline College/university & 77 & 14 & $14.52(7.12-29.61)$ & $4.84(2.03,11.52)^{* *}$ \\
\hline \multicolumn{5}{|l|}{ Husband educational status } \\
\hline Can't read and write & 23 & 58 & 1 & 1 \\
\hline Primary school & 76 & 85 & $2.25(1.27-4.00)$ & $1.18(0.59,2.35)$ \\
\hline Secondary school & 140 & 30 & $11.76(6.30-21.95)$ & $6.28(3.01,13.07)^{*}$ \\
\hline College/university & 142 & 13 & $27.54(13.07-58.05)$ & $11.28(4.65,27.34)^{* *}$ \\
\hline \multicolumn{5}{|l|}{ Women's Occupation } \\
\hline House wife & 78 & 98 & 1 & 1 \\
\hline Self employed & 157 & 62 & $3.18(2.09-4.83)$ & $1.88(1.09,3.24)^{*}$ \\
\hline Government employee & 146 & 26 & $7.05(4.22-11.77)$ & $4.10(2.11,7.96)^{* *}$ \\
\hline \multicolumn{5}{|l|}{ Exposure to media } \\
\hline Have exposure & 351 & 139 & $3.95(2.40-6.51)$ & \\
\hline No exposure & 30 & 47 & 1 & \\
\hline \multicolumn{5}{|l|}{ Husband occupation } \\
\hline Not employed & 23 & 58 & 1 & 1 \\
\hline Self employed & 174 & 96 & $4.57(2.65-7.87)$ & $1.47(0.71,3.03)$ \\
\hline Government employee & 184 & 32 & $14.50(7.86-26.73)$ & $2.7(1.23,5.94)^{*}$ \\
\hline \multicolumn{5}{|l|}{ Attitude towards FP methods } \\
\hline Have favorable attitude & 105 & 24 & $2.56(1.58-4.16)^{*}$ & \\
\hline Have no favorable attitude & 276 & 162 & 1 & \\
\hline \multicolumn{5}{|l|}{ Number of living children } \\
\hline No children & 68 & 21 & 1 & \\
\hline $1-2$ & 231 & 111 & $0.64(0.37-1.10)$ & \\
\hline $3-4$ & 64 & 38 & $0.52(1.27-0.97)$ & \\
\hline$>5$ & 18 & 16 & $0.34(0.15-0.79)^{*}$ & \\
\hline
\end{tabular}

**P-value $<0.001,{ }^{*} p$-value $<0.05$

$[16,26,27]$. The findings of this study also suggest that there is a positive relationship between women's age and their decision-making power on family planning use, which is in line with previous studies in Ethiopia [22, 23, 28]. Paradoxically, in the national study of Ethiopia 2011 [5], women's decision-making power on family planning use decreased when they approached menopause. This discrepancy could be due to the difference in study settings, cultural values, and experience about family planning use.

This study has the following potential limitations. First, information on socio-demographic characteristics, knowledge, and attitudes towards family planning use intended to be gathered from husbands was obtained from the women. Second, the relationship between women's autonomy and family planning use was 
measured by self-report, which is likely to be subjected to social desirability bias. Regarding participants, the study excluded women living in union, but not legally married. Moreover, attitude related to the reproductive history of the women was not supported with qualitative data.

\section{Conclusion}

The magnitude of women's decision making power on family planning among currently married reproductive age women was found to be high in this study. Factors, such as women's and husbands' primary and above education, age category (34-44 years), occupational status of women and their husbands were found to be statistically significantly related with the decision making power of women on family planning utilization. We recommend promoting parental adult education and engaging women on out of house employment.

\section{Competing interests}

The authors declare that they have no competing interests.

\section{Authors' contributions}

$A D$ designed the study, questionnaire, objective, method, analyzed the statistical analysis, and drafted the paper. ZB, MK and YA participated in the overall development of questionnaire, objective, method, and analysis and write up of the manuscript. All authors gave suggestions, read the manuscript, agreed on its content and approved the final version.

\section{Acknowledgement}

Bench-Maji Zonal Health Department, Mizan-Aman City Administration Health office, study participants, data collectors and supervisors are acknowledged for their cooperation and assistance.

\section{Author details}

${ }^{1}$ Woman, Children and Youths Affairs Bureau, Bench Maji Zone, Mizan Aman, Ethiopia. ${ }^{2}$ Institute of Public Health, College of Medicine and Health Sciences University of Gondar, Gondar, Ethiopia.

Received: 28 October 2015 Accepted: 29 February 2016

Published online: 08 March 2016

\section{References}

1. Abegunde D, Orobaton N, Shoretire K, Ibrahim M, Mohammed Z, Abdulazeez J, et al. Monitoring maternal, newborn, and child health interventions using lot quality assurance sampling in Sokoto State of northern Nigeria. Global Health Act. 2015;8:27526. Epub 2015/10/13. eng

2. Navot N, Jorgenson AG, Vander Stoep A, Toth K, Webb SJ. Family planning and family vision in mothers after diagnosis of a child with autism spectrum disorder. Autism. 2015;22. Epub 2015/09/24. Eng.

3. Onarheim $\mathrm{KH}$, Taddesse M, Norheim OF, Abdullah M, Miljeteig I. Towards universal health coverage for reproductive health services in Ethiopia: two policy recommendations. Int J Equity Health. 2015;14(1):86. Pubmed Central PMCID: PMC4588686, Epub 2015/10/01. eng.

4. Yigzaw M, Zakus D, Tadesse $Y$, Desalegn M, Fantahun M. Paving the way for universal family planning coverage in Ethiopia: an analysis of wealth related inequality. Int J Equity Health. 2015;14(1):77. Pubmed Central PMCID: PMC4568578, Epub 2015/09/16. eng.

5. Central Statistical Agency [Ethiopia], ICF International. Ethiopia demographic and health survey 2011. Addis Ababa and Calverton: Central Statistical Agency and ICF International; 2012.

6. Central Statistical Agency [Ethiopia]. Ethiopia mini demographic and health survey 2014. Addis Ababa: Central Statistical Agency [Ethiopia]; 2014

7. Bogale B, Wondafrash M, Tilahun T, Girma E. Married women's decision making power on modern contraceptive use in urban and rural southern Ethiopia. BMC Public Health. 2011;11:342. Pubmed Central PMCID: PMC3114727, Epub 2011/05/21. eng.
8. Bourey C, Stephenson R, Bartel D, Rubardt M. Pile sorting innovations: exploring gender norms, power and equity in sub-Saharan Africa. Glob Public Health. 2012;7(9):995-1008. Epub 2012/08/08. eng.

9. Wado YD. Women's autonomy and reproductive healthcare-seeking behavior in Ethiopia. Calverton: ICF International; 2013.

10. Europe C. Family planning \& women's empowerment, Fact sheet. 2012.

11. Carr B, Gates MF, Mitchell A, Shah R. Giving women the power to plan their families. Lancet. 2012;380(9837):80-2. Epub 2012/07/13. eng.

12. Studies ESoP. Gender inequality and women's empowerment, In-depth Analysis of the Ethiopian Demographic and Health Survey 2005. 2008.

13. Federal Democratic Republic of Ethiopia Population Census Commission. Summary and Statistical Report of the 2007 population and Housing Census; Population Size by Age and Sex. Addis Ababa, Ethiopia: Central Statistical Agency; 2008.

14. Do M, Kurimoto N. Women's empowerment and choice of contraceptive methods in selected African countries. Int Perspect Sex Reprod Health. 2012;38(1):23-33. Epub 2012/04/07. eng.

15. Family Care International. The safe motherhood initiative 1987-2005, Safe Motherhood. 2005.

16. Teferi E, Garoma S. Married women's access to resources and decision making power in Nekemte Town, West Ethiopia. Elective Med J. 2014;2(4):7.

17. Ethiopian Society of Population Studies. Gender inequality and women's empowerment, In-depth analysis of the Ethiopian demographic and health survey 2005. Addis Ababa: Ethiopian Society of Population Studies; 2008.

18. Jan M, Akhtar S. An analysis of decision making power among married and un married women. Stud Home Comm Sci. 2008:2:43-50.

19. Kinoshita R. Women's domestic decision - making power and contraceptive use in rural Malawi. Reprod Health. 2003;2:8.

20. Saleem S, Bobak M. Women's autonomy, education and contraception use in Pakistan: a national study. Reprod Health. 2005;2(8):1-8.

21. Erci B. Women's efficiency in decision making and their perception of their status in the family. Public Health Nurs. 2003;20(1):65-70.

22. Kebede Y. Contraceptive prevalence in dembia district, northwest Ethiopia. Ethiop J Heal Dev. 2006;20(1):32-8.

23. Speizer IS, Whittle L, Carter M. Gender relations and reproductive decision making in Honduras. Int Fam Plan Perspect. 2005;131-9.

24. Tuloro T, Deressa W, Ali A, Davey G. The role of men in contraceptive use and fertility preference in Hossana Town, southern Ethiopia. Ethiop J Heal Dev. 2009;20(3):152-9.

25. Tilahun T, Coene G, Luchters S, Kassahun W, Leye E, Temmerman M, et al. Family planning knowledge, attitude and practice among married couples in Jimma Zone, Ethiopia. PLoS One. 2013;8(4):e61335.

26. Patrikar SR, Basannar DR, Sharma MS. Women empowerment and use of contraception. Med J Armed Forces India. 2014;70:253-6.

27. Tarekegn SM, Lieberman LS, Giedraitis V. Determinants of maternal health service utilization in Ethiopia: analysis of the 2011 Ethiopian demographic and health survey. BMC Pregnancy Childbirth. 2014;14:161. Pubmed Central PMCID: PMC4022978, Epub 2014/06/03, eng.

28. Mesfin $\mathrm{G}$. The role of men in fertility and family planning program in Tigray Region. Ethiop J Health Dev. 2002.

Submit your next manuscript to BioMed Central and we will help you at every step:

- We accept pre-submission inquiries

- Our selector tool helps you to find the most relevant journal

- We provide round the clock customer support

- Convenient online submission

- Thorough peer review

- Inclusion in PubMed and all major indexing services

- Maximum visibility for your research

Submit your manuscript at www.biomedcentral.com/submit 